\title{
MONOCULTIVOS DE EUCALIPTO, REFLEXIVIDADE E ARENA: DIÁLOGOS INTERDISCIPLINARES EM AMBIENTE E SOCIEDADE.
}

\section{PLANTACIONES DE EUCALIPTO, REFLEXIVIDAD Y DISCUSIÓN: DIÁLOGO INTERDISCIPLINARIO SOBRE EL MEDIO AMBIENTE Y LA SOCIEDAD.}

\section{EUCALYPTUS PLANTATIONS, REFLEXIVITY AND DISCUSSION: INTERDISCIPLINARY DIALOGUE ON ENVIRONMENT AND SOCIETY.}

\author{
Ramon Felipe Bicudo da SILVA ${ }^{1}$ \\ Francisco ARAOS-LEIVA ${ }^{2}$ \\ Juliana Sampaio FARINACI ${ }^{3}$ \\ Leila da Costa FERREIRA ${ }^{4}$
}

\begin{abstract}
RESUMO: Em muitas regiões o impacto social e ambiental dos monocultivos de eucalipto continua sendo amplamente debatido e, por esta razão, essa atividade agroindustrial florestal tem incentivado o desenvolvimento de diversas pesquisas científicas, o surgimento de mecanismos de mercado (selos verdes e certificações) para que o setor atenda às demandas da sociedade e do comércio, bem como o embate entre diferentes atores (sociedade civil, comunidade cientifica e setor florestal) envolvidos. Nesse contexto, onde se enfrentam diferentes discursos e posicionamentos, construídos através do processo histórico de cada grupo social na sua relação com o modelo de desenvolvimento, se firmam as oportunidades para o diálogo e negociação, elementos chave para uma condução, com ampla participação, do atual modelo de desenvolvimento para uma nova plataforma orientada nas bases da sustentabilidade. Este artigo busca discutir alguns elementos teóricos da modernidade que
\end{abstract}

\footnotetext{
${ }^{1}$ Biólogo (UNESP/Bauru), Doutorando (UNICAMP), Msc-Engenharia Agronômica (UNESP/Botucatu), Especialista em Gestão Ambiental (UFSCar). Educação ambiental, pesquisa social, gestão ambiental de paisagens urbanas e agrícolas, sensoriamento remoto e geoprocessamento. Integrante do Núcleo de Estudos e Pesquisas Ambientais - NEPAM/UNICAMP. Doutorando em Ambiente e Sociedade. ramonbicudo@gmail.com 2 Antropólogo Social (Universidade do Chile). Doutorando-NEPAM/UNICAMP. Conflitos ambientais, populações tradicionais e governança ambiental. Participa desde o ano 2005 no Centro de Desarrollo Sustentable de Pichilemu, organização civil que promove o desenvolvimento integral do borde costeiro no Chile. franciscoaraos@gmail.com

${ }^{3}$ Profa. Dra., Ambiente e Sociedade, NEPAM/UNICAMP. Msc em Genética e Biologia Molecular (UNICAMP). Graduação em Biologia (UNICAMP). Pesquisadora Colaboradora e pós-doutoranda no (NEPAM/UNICAMP). Atua em pesquisa, ensino e extensão com foco nas interações homem-ambiente. jsfarinaci@gmail.com.

${ }^{4}$ Prof. Dra. do Instituto de Filosofia e Ciências Humanas - IFCH/UNICAMP. Graduação em Ecologia (UNESP). Msc. em Sociologia (UNICAMP). Doutorado em Ciências Sociais (UNICAMP). Pós-doutorado na Universidade do Texas-EUA em Políticas Públicas e Ambiente e Pós-Doutorado na Universidade de York Inglaterra em Teoria Social e Ambiente. Livre Docência em Sociologia Ambiental. Membro do Associate Faculty of the Earth System Governance Project. Profa. visitante no Programa top China-Shangai Jio Tong University/ Summer Course - China. Coordenadora do Grupo de Estudos Brasil/China junto ao Centro de Estudos Avançados da UNICAMP. Atua nos temas: sociologia ambiental, sustentabilidade, interdisciplinaridade, questão ambiental e teoria social. Pesquisadora CNPq-1D. Representante da UNICAMP junto ao WUN Global Challenges/Adaptating to climate change desde agosto de 2012. leilacf@unicamp.br
} 
permitam problematizar as questões socioambientais e aplica, sobre a questão da eucaliptocultura, conceitos da sociologia ambiental (modernização reflexiva, arena ambiental e sociedade de risco) a fim de criar um arcabouço conceitual que contribua para: (1) compreender o conflito entre projetos e visões distintas de desenvolvimento; (2) oferecer elementos para pensar a superação dos dilemas socioambientais postos pela modernidade.

Palavras chave: interdisciplinaridade, modernidade, risco, conflito ambiental, eucaliptocultura.

RESUMEN: En muchas regiones, los impactos sociales y ambientales del monocultivo de eucalipto siguen siendo ampliamente debatido y, por esta razón, esta actividad agroforestal ha favorecido el desarrollo de diversos estudios científicos, la creación de mecanismos de mercado (sellos verdes y certificaciones) para que este sector cumpla con las exigencias de la sociedad y el comercio, así como conflictos entre los diferentes actores (sociedad civil, la comunidad científica y el sector forestal) involucrados. En este contexto, en el que se enfrentan diversos discursos y posiciones, han emergido oportunidades para el diálogo y la negociación del modelo actual de desarrollo, orientados hacia la sustentabilidad. Este trabajo discute algunos elementos teóricos de la modernidad que permiten problematizar las cuestiones socioambientales en la actualidad, aplicando, sobre la la industria forestal del eucalyptus, conceptos de la sociología ambiental - modernización reflexiva, arena ambiental y sociedad del riesgo -, con el objetivo de construir un marco conceptual y analítico que permita: (1) comprender el conflict entre los proyectos y visiones diferentes acerca del desarrollo, (2) proporcionar elementos para superar los dilemas ambientales que plantea la modernidad.

Palabras-clave: Interdisciplinaridad, modernidad, riesgo, conflicto ambiental, cultivo de eucaliptos.

ABSTRACT: In many regions the social and environmental impacts promoted by eucalyptus monoculture are still widely debated. For this reason, this forestry agro-industrial activity has been stimulating the development of several scientific researches, the appearing of trade market mechanisms (green labeling and certification) that enable this sector to comply with demands from civil society and from the market, as well as promoting the opposition between different actors (civil society, scientific community and forestry sector) involved. In this context, where different speeches and positions - built through the historic process for each social group in their relationship with the model of socio-economic development - face each other, opportunities for dialogue and negotiation are settled, the key elements for the construction, with wide participation from society, of a new development platform oriented by the basis of sustainability. This paper seeks to analyze the complexity represented by modernity in the axis of socio-environmental issues, and applies elements of environmental sociology (reflexive modernization, environmental arena and risk society) to the case of eucalyptus monoculture in order to create a conceptual model which contributes to: (1) understanding the process of facing between different development projects and visions; (2) offering elements for discussing the overcoming of socio-environmental dilemmas posed by modernity.

Keywords: interdisciplinarity, modernity, risk, environmental conflict, eucalyptus cultivation. 


\section{INTRODUÇÃO}

Há consenso entre cientistas, políticos e associações civis, de que a velocidade das mudanças ambientais é cada vez maior, e que a ação do homem é a principal causa deste fenômeno (MORAN e OSTROM, 2010; FBDS, 2011). Os aumentos do número e da intensidade de eventos climáticos extremos aparecem, assim, como efeito colateral do crescimento econômico, do desenvolvimento industrial, do crescimento populacional e da crescente demanda por recursos naturais para o suprimento das necessidades humanas.

Esse quadro tem gerado a emergência do conceito de risco como uma categoria central na construção da sociedade contemporânea, a partir do reconhecimento do papel do desenvolvimento industrial como potencial produtor da própria autodestruição da sociedade através de suas consequências no meio ambiente (BECK, 1992). Este problemático encontro entre os riscos produzidos pelo desenvolvimento industrial com os próprios mecanismos que os produzem é o que o sociólogo alemão Ulrich Beck denomina modernização reflexiva e que, segundo ele, caracteriza um novo momento na sociedade contemporânea (BECK et al., 1995).

Acreditamos ser possível observar analiticamente este processo, no caso da indústria do eucalipto no Brasil e em outros países da América do Sul, a partir do desenvolvimento de uma arena $^{5}$ ambiental específica (HANNIGAN, 2006), onde se confrontam o crescimento econômico, a tecnificação e a certificação desta agroindústria, com as demandas e argumentos de grupos ambientalistas associadas à condição da monocultura, à inadequação dos cultivos de eucalipto como refúgio e habitat para a vida selvagem - os chamados "desertos verdes"- e ao consumo excessivo de água (VITAL, 2007).

Nesse sentido, abordar a indústria do eucalipto a partir da modernização reflexiva nos permite entender este sistema agroindustrial como um fenômeno socioambiental multifacetado, no qual convergem diversos atores e perspectivas (FERREIRA, 2006). Com o objetivo de ir para além de uma leitura unidirecional na relação entre desenvolvimento econômico e meio ambiente, a nossa abordagem apresenta uma possibilidade analítica para entender as dinâmicas sócio-políticas que estão na base dos empreendimentos silviculturais e

\footnotetext{
${ }^{5}$ Chamamos atenção para o conceito de arena (HANNIGAN 2006; OSTROM 1990; FERREIRA, 2004) como o espaço-sistema no qual os diferentes atores envolvidos constroem e dirigem seus argumentos no processo de formulação e tomada de decisão.
} 
as possibilidades para um diálogo mais amplo, não polarizado, apresentado pela interdisciplinaridade em ambiente e sociedade.

Reconhece-se, também, que os mais sérios problemas globais de desenvolvimento e meio ambiente que o mundo enfrenta decorrem de uma ordem econômica caracterizada pela produção e consumo sempre crescentes, o que esgota e degrada os recursos naturais, além de criar e perpetuar desigualdades gritantes entre as nações, bem como dentro delas, em que $20 \%$ das pessoas consomem $80 \%$ dos recursos mundiais (RUTKOWSKI et al., 2008).

\section{CONTEXTUALIZAÇÃO HISTÓRICA DO EUCALIPTO NO BRASIL}

Foi na primeira metade do século XIX que chegaram ao Brasil as primeiras mudas de eucalipto vindas da Austrália, um gênero (Eucalyptus) representado por diversas espécies e que se tornou um dos recursos florestais mais rentáveis e também polêmicos nas últimas décadas do século XX (VITAL, 2006). O plantio do eucalipto em escala comercial data da primeira década do século XX (1904). Inicialmente, foi introduzido como monocultura destinada a suprir a demanda de lenha para combustíveis das locomotivas e dormentes para trilhos da Cia. Paulista de Estradas de Ferro (MORA e GARCIA, 2000).

Dos 470 mil hectares (ha) de eucaliptos plantados no país entre 1909 e 1966, 80\% concentravam-se no estado de São Paulo. A partir de estudos iniciados em 1903 na cidade de Jundiaí/SP, pelo pesquisador Edmundo Navarro de Andrade, com a finalidade de viabilizar o plantio do eucalipto em larga escala, a Cia. Paulista de Estradas de Ferro iniciou os primeiros plantios de eucalipto em escala comercial (MARTINI, 2010).

Apesar do pioneirismo da Cia. Paulista de Estradas de Ferro nas pesquisas para utilização de celulose do eucalipto para a produção de papel na década de 1920 (MARTINI, 2010), foi no final da década de 1950 que Cia. Suzano marcava o início do comércio internacional brasileiro com a produção de papel $100 \%$ à base de celulose de eucalipto. Esta iniciativa aconteceu frente aos interesses do país em encontrar alternativas à importação da celulose européia (MORA e GARCIA, 2000).

Entre a década de 1960 até o início da década de 1980, houve um grande crescimento das áreas cultivadas de eucalipto para o abastecimento das indústrias siderúrgicas e de papel e celulose, por meio da política de incentivos fiscais ao reflorestamento, adotada pelo regime militar que governou o país entre 1964 e 1985. Nessa época a área plantada com eucalipto passou de 500 mil ha para 3 milhões de ha (CARDOSO, 2011). Áreas de floresta nativa 
foram derrubadas nesta época para dar lugar a áreas cultivadas de eucalipto (FREITAS et al., 2012).

Até o início da década de 2000, o Brasil era um importador de carvão mineral e coque (fontes de energia imprescindíveis para a siderurgia), sobretudo da China e da Rússia. A partir dessa década, especialmente a China intensifica seu processo de desenvolvimento, com forte componente na construção civil, e torna-se a maior importadora de ferro-gusa e consumidora de suas próprias fontes energéticas, o que levou à diminuição da exportação chinesa de carvão mineral e coque.

Esse processo levou a uma mudança na correlação de forças no mercado internacional de insumos e produtos siderúrgicos, pois encareceu o valor do coque e do carvão mineral chineses. Isso fez do carvão de origem vegetal um produto rentável e, sobretudo, uma alternativa à compra do coque e do carvão minerais chineses para a siderurgia. Isso levou o Brasil a um ciclo de expansão e consolidação do uso do eucalipto como fonte para a produção de carvão vegetal.

\section{REFLEXIVIDADE: EUCALIPTO, AMBIENTE E SOCIEDADE}

A partir da década de 1980, quando o Brasil atravessava o processo de redemocratização (resultado do fim do regime militar), emergiram movimentos sociais que demandavam maiores espaços de participação política, assim como o reconhecimento dos diversos direitos de cidadania: movimentos do Negro, do Indígena, dos Homossexuais, Feministas e os movimentos Ecológicos (ALVAREZ et al., 2001).

Nesse período, a sociedade civil organizada dá inicio a pressões contra órgãos públicos e empresas florestais, para que estes tomassem medidas responsáveis a fim de sanar os impactos ambientais e sociais promovidos pelo modelo de produção de eucalipto implantado durante a década de 1970. Sobre esse período, é importante ressaltar que o mundo estava vivendo uma nova fase de desenvolvimento econômico, baseado na expansão e interdependência dos mercados em uma escala global, processo que foi acompanhado da construção de um discurso ambiental global questionador do crescimento sem limites e do modelo de desenvolvimento.

$\mathrm{O}$ entendimento de mundo, o reconhecimento das crises ambientais planetárias, questões de saúde e de justiça ambiental passavam a fazer parte da pauta da agenda 
internacional, o que refletiu no pensamento contemporâneo das sociedades latinoamericanas, assim como descreve Guimarães (2002: 128):

"A abertura de espaço para a construção de uma ecopolítica está vinculada à evolução da agenda dos desafios ambientais de América Latina e Caribe da década de 80 e inicio dos 90, e com as mudanças que a humanidade enfrentou neste mesmo período em função da globalização." (tradução livre).

Principalmente no fim da década de 1990 e anos 2000, não apenas no Brasil, mas em diversos outros países, intensificaram-se as discussões ao redor da polêmica sobre os impactos ambientais e sociais do eucalipto. No Brasil, a rede "Deserto Verde", grupo formado por cerca de 80 entidades da sociedade civil, se uniu para acusar que o plantio de eucalipto no estado do Espírito Santo devastava mata nativa, provocava seca de rios, desequilíbrio ambiental e êxodo rural. Esse grupo conseguiu, por meio de uma lei estadual em 2001, proibir a expansão do plantio no estado.

Nesse mesmo estado, a FASE Espírito Santo (Federação de órgãos para assistência social e educacional), em conjunto com ONGs européias, internacionalizaram a luta contra o eucalipto. Em 2007, na Real Academia de Silvicultura da Suécia, durante reunião com as maiores indústrias do setor florestal, fizeram um depoimento sobre os males da indústria de celulose e das monoculturas de eucalipto sobre o ambiente e sobre as populações rurais. Sobre este ponto, Winnie Overbeek (OLIVEIRA, 2007: 1), representante da FASE, refletiu: "A globalização das transnacionais é correspondida pela internacionalização das lutas sociais."

No Chile, durante a década de 1990, as comunidades indígenas Mapuches deflagraram uma série de protestos contra empresas florestais, que se estendem até a atualidade. Entre os motivos desses protestos está a ocupação de terras indígenas pelas empresas florestais. Nessas terras, especialmente na região de Bío Bío e Araucanía, onde predominam solos de alta fertilidade, a ocupação por monoculturas de eucalipto tem provocado impactos ao ecossistema do qual os indígenas dependem para sua sobrevivência (CHAVES, 2008). A expansão das florestas de eucalipto no Chile não somente degradou as terras agrícolas e as florestas nativas, mas também o território tradicional indígena, que fornece as bases materiais e espirituais para a existência deste povo (VELOSO, 2011).

Esse cenário construído em torno da indústria do eucalipto e sobre os riscos ambientais e sociais relacionados ao seu sistema industrial, que se consolidou nas últimas décadas do século XX, apresenta evidências de uma transição, como argumenta Beck (1995), do período industrial para o período de risco da modernidade, que ocorre de forma indesejada e com um padrão de efeitos colaterais latentes. 
Faz sentido, sobre este ponto e sobre o caso do depoimento da FASE na Suécia, pensar na dimensão "claro-escuro" da globalização, posta por Guimarães (2002), onde, na zona das "sombras", aquilo que não seja conveniente para o mundo globalizado poder ser ignorado. No caso, o comportamento indiferente do setor florestal (observado pelos movimentos sociais) frente à crise socioambiental promovida por suas atividades agroindustriais.

Sobre a reunião na Real Academia de Silvicultura da Suécia, Winnie Overbeek comenta (OLIVEIRA, 2007: 1):

"Era um ambiente muito formal, com muitos representantes das empresas; não nos deixaram falar mais que um minuto. Foi difícil. Mesmo assim, apenas o fato de haver um depoimento sobre os males da indústria de celulose e seus monocultivos de eucalipto, teve força. Conseguimos quebrar a visão de que investir aqui (Brasil) é simples, porque para eles é como se tudo estivesse sempre bem."

Sobre esse mesmo ponto, o da dimensão “claro-escuro” da globalização, um episódio ocorrido nos Estados Unidos traz evidências do clamor vindo de partes da sociedade, pela necessidade de o mundo globalizado encarar a "si mesmo", suas dimensões, de modo a se auto-confrontar. Em 1999, meses antes de uma reunião da Organização Mundial do Comércio (OMC) em Seattle, centenas de organizações populares reuniram-se em uma rede que ficou conhecida por "Coalizão de Seattle". Esta rede realizou, durante a reunião, uma série de manifestações, com objetivo de fazer o mundo conhecer os pontos de vista que eram ignorados (direitos humanos, feminismo, justiça ambiental, direitos culturais) pelo escopo das questões sobre a globalização econômica (CAPRA, 2002).

Giddens (1991) não estava errado quando afirma ser, a modernidade, uma faca de dois gumes. Ao mesmo tempo em que a modernidade trouxe uma série de benefícios e oportunidades aos seres humanos, também trouxe consigo um lado sombrio.

\section{CIÊNCIA, ECONOMIA E SOCIEDADE}

Frente aos conflitos socioambientais que sugiram na órbita do tema eucalipto, é relevante a reflexão sobre o risco. Uma situação que envolve diferentes atores sociais sobre um tema que é controverso e polêmico, em que não há consenso entre os diferentes grupos que fazem oposição, constitui a base para a formação de uma arena sociopolítica, onde os processos de contestação focam na presença ou ausência de um mal gerado pelo objeto de risco (HANNIGAN, 2006). 
As diferentes formas de debater uma temática estão ligadas às bases ideológicas e aos modelos mentais tradicionais da população (SILVA e MENDES, 2005) e os argumentos de risco podem, frequentemente, entrar em conflitos de bases ideológicas (HANNIGAN, 2006). Enquanto grupos de orientação social ou ambientalista argumentam sobre os riscos associados ao eucalipto, como, por exemplo, a erosão e o ressecamento do solo, a perda de biodiversidade e o êxodo rural, por outro lado há aqueles que entendem como riscos os danos à economia e à sociedade, caso o agronegócio florestal sofra com medidas orientadas ao controle e limitação que enfraqueçam o desenvolvimento do setor.

Desta forma, observamos uma série de argumentos apresentados pelas ciências ambientais, por estudos econômicos e por movimentos sociais, que constroem os discursos e orientam os atores que estão debatendo a eucaliptocultura. Sobre este ponto, este artigo destaca alguns aspectos do debate no âmbito da arena ambiental posta pelo setor agroindustrial de base florestal.

Ciência: As pesquisas científicas no âmbito das dimensões ambientais, atualmente possuem uma base de argumentação sólida confrontando mitos e parte das percepções ambientais locais sobre os danos e riscos ambientais da cultura do eucalipto (TREVISAN, 2010; SILVEIRA, 2005; PINTO e PENIDO, 2010; OLIVEIRA, 1997; LIMA, 2010).

Com interesse em esclarecer as relações das florestas de eucalipto com a biodiversidade local, pesquisas científicas e inventários de fauna e flora têm-se desenvolvido.

Sobre este tema, pesquisas vêm demonstrando que as áreas cultivadas com eucalipto fornecem abrigo à fauna silvestre (TIMO, 2009; MAZZOLLI, 2010). Em resposta ao aumento na população de Puma concolor (puma, onça-parda ou suçuarana) em uma região no Sul do Brasil, por exemplo, Mazzolli (2010) realizou um estudo de campo com intuito de verificar os fatores responsáveis por este fenômeno. Concentrado em uma área de produção florestal de eucalipto, o estudo identificou considerável relação positiva entre os plantios florestais e a fauna silvestre. De acordo com resultados obtidos, os maciços de eucalipto têm exercido as funções de área de caça e habitat para os pumas. Além disso, as atividades de fiscalização, controle e monitoramento dos maciços florestais e de suas zonas de entorno coíbem atividades humanas de caça.

Em relação a atividades ilegais de desmatamento, o reflorestamento com espécies exóticas, como o eucalipto, veio contribuir no sentido de reduzir taxas de desmatamento de florestas nativas (BAENA, 2005). Esse argumento segue como parte importante no discurso 
do setor florestal, uma vez que a utilização de carvão proveniente de florestas plantadas representa uma alternativa positiva a contribuir no combate ao desmatamento ilegal.

Sobre a polêmica em relação ao consumo excessivo de água pelas florestas de eucalipto, foi a partir da análise de resultados disponíveis sobre aspectos fisiológicos - taxa de transpiração, dinâmica dos estômatos, índice de área foliar, eficiência do uso da água, perdas por interceptação e balanço hídrico - que pesquisadores como Andreassian (2004), Whiteheade e Beadle (2004) e Lima (2010) verificaram que o eucalipto é uma espécie florestal que não consome mais água por unidade de biomassa produzida do que qualquer outra espécie florestal.

Outra questão a ser considerada sobre este aspecto está no âmbito da paisagem florestal que, podendo ser uma floresta nativa ou um plantio de eucalipto, demandará quantidades de água para a manutenção de seus indivíduos. Esse tema é abordado em diversas pesquisas florestais e em estudos com a finalidade de comparar as taxas de evapotranspiração ${ }^{6}$ entre diferentes formações florestais (CANNELL, 1999; COSTA e FOLEY, 1999; ALMEIDA e SOARES, 2003; BALBINOT et al., 2008). Almeida e Soares (2003) realizaram um estudo a partir de um banco de dados hidrológicos (série temporal de 6 anos) em uma bacia hidrográfica onde as medições foram realizadas em um plantio de eucalipto e em uma floresta nativa (Mata Atlântica). Este estudo mostrou que, para a região estudada, os plantios de eucalipto se comparam à Mata Atlântica quanto à evapotranspiração e ao uso de água do solo.

Essas evidências científicas apresentam forte argumentação, a partir de determinados aspectos ambientais inerentes ao debate sobre a eucaliptocultura, que impulsionam o desenvolvimento desse setor e se contrapõem ao discurso de segmentos da sociedade que historicamente construíram o argumento dos "desertos verdes" ou do excessivo consumo de água.

Tais resultados têm reforçado o argumento de que é possível haver a produção de eucalipto em bases ecologicamente sustentáveis. No entanto, generalizações sobre o tema devem ser recebidas com ressalva, uma vez que essa cultura está concentrada em diversas regiões do mundo e se desenvolve nas mais variadas condições ambientais (VITAL, 2007). Vital (2007: 236) também faz uma observação sobre os consensos e divergências a respeito do tema:

\footnotetext{
${ }^{6}$ Evapotranspiração é a perda de água do solo por evaporação e a perda de água da planta por transpiração. Esses dois processos ocorrem concomitantemente e recebem o nome de evapotranspiração (CAMARGO e CAMARGO, 2000).
} 
"Parece, de fato, que as controvérsias e debates giram mais em torno de questões sociopolíticas... muitos estudos científicos sobre os temas relacionados ao eucalipto e o meio ambiente costumam apontar na mesma direção, sinalizando mais consenso do que discussão."

Economia: Impulsionadas por preocupações ambientais, principalmente na última década, empresas de todos os segmentos, principalmente aquelas atreladas ao mercado e comércio internacional, começaram a adotar políticas ambientais, entre outros motivos, pelo interesse em maior competitividade em mercados internacionais. O segmento florestal segue esta tendência, como pode ser observado em diversos projetos liderados pela Fundação Brasileira para o Desenvolvimento Sustentável ${ }^{7}$.

Desde as últimas décadas do século XX, a problemática ambiental na América Latina esteve marcada por sua forte inserção socioeconômica na ordem internacional, tendo sido o desenvolvimento desta região atrelado aos centros hegemônicos do poder (GUIMARÃES, 2002), assim como descrevem Blanco e Mendes (2006: 51-52):

"Durante os anos 1990, os projetos com forte envolvimento e comprometimento dos ecossistemas têm sua justificativa na matriz neoliberal. A execução se fundamenta na necessidade de um crescimento econômico que incorpore uma determinada região ao primeiro mundo utilizando o conceito de 'sustentável' ou 'sustentabilidade' para projetos economicamente rentáveis em longo prazo, produzindo benefícios econômicos: ao turismo, à integração regional, ou ao manejo das florestas nativas." (tradução livre).

Essa característica, reflexo do processo globalizante da modernidade, agora cria as oportunidades para que as grandes corporações multinacionais ditem as "regras do jogo" da sustentabilidade, exigindo certificações de responsabilidade social e ambiental para toda a cadeia de suprimento de matéria-prima e para processos fabris.

Segundo relato da secretária-executiva do Forest Stewardship Council Brasil ${ }^{8}$ (FSC), o crescimento da certificação dos produtos de origem florestal é impulsionado mais pelas políticas corporativas de compra do que pela consciência dos consumidores (ADEODATO, 2011). Estas são evidências da tendência de internacionalização do setor florestal e da constituição de uma complexa rede político-econômica centrada na reorganização dos meios produtivos, que, no entanto, continuam sobre a lógica e comando do sistema orientado pela economia de mercado.

\footnotetext{
${ }^{7}$ A missão da FBDS é difundir as melhores práticas de meio ambiente e sustentabilidade e influenciar os nossos públicos de interesse por meio da geração de conhecimento, contribuição na formulação de políticas públicas e realização de projetos de consultoria.

${ }^{8}$ FSC Brasil: Organização não governamental cuja missão é difundir e facilitar o bom manejo das florestas brasileiras conforme Princípios e Critérios que conciliam as salvaguardas ecológicas com os benefícios sociais e a viabilidade econômica.
} 
De acordo com dados do estudo Global Eucalyptus Map, realizado pelo GIT Forestry Consulting (IGLESIAS-TRABADO e WILSTERMANN, 2008), a superfície da Terra já é coberta por 19.507.670 hectares de eucalipto, sendo a Índia (3.942.600 ha), o Brasil (3.751.857 ha) e a China (2.609.700 ha) os maiores produtores desta matéria prima. Ainda de acordo com o mesmo estudo, Peru, Chile, Argentina e Uruguai seguem como importantes produtores de eucalipto, juntos contabilizando 2.138.124 ha ou aproximadamente $10 \%$ da produção total mundial.

De acordo com dados da Food and Agriculture Organization of the United Nations (FAO, 2009), a movimentação econômica mundial entre exportações e importações dos produtos florestais madeireiros foi, em 2008, da ordem de 198 bilhões de dólares e 208 bilhões de dólares, respectivamente. Mesmo que o destaque tenha sido para países com longa tradição no mercado no setor, como Estados Unidos e Canadá, onde a base florestal está na exploração de espécies nativas de seus países, o Brasil teve nesse cenário uma participação com 8 bilhões de dólares em exportações e 1,5 bilhão de dólares em importações (SOARES $e t$ al., 2011). No caso brasileiro, as florestas de eucalipto suprem mais de $70 \%$ da produção de celulose, mais de $70 \%$ da produção de carvão vegetal, $100 \%$ da produção de chapa de fibra e $30 \%$ da produção de chapa de fibra aglomerada (REVISTA MADEIRA, 2003).

É possível reconhecer que o setor agroindustrial com base na produção florestal tenha crescido mundialmente e, no caso brasileiro, com o uso predominante do eucalipto, oferecendo oportunidades de negócio e crescimento econômico.

Sociedade: Com a reconhecida importância deste sistema agroindustrial para o desenvolvimento econômico e com os impactos ambientais dos monocultivos de eucalipto sobre a investigação científica, ainda permanecem divergências entre os segmentos das ciências ambientais, de determinados grupos da sociedade civil e de representantes do setor florestal.

A tese aqui defendida é a de que a polarização dos discursos, reflexo do antagonismo que há entre os diferentes interesses vindos de cada grupo, prejudicam o diálogo, comprometendo as possibilidades de negociação para a viabilização destes empreendimentos de forma a atender também os setores da sociedade preocupados com os riscos ambientais e sociais.

Sobre este ponto, tomemos como exemplo o caso do Vale do Paraíba/SP, onde o temor da sociedade civil em relação às incertezas sobre os impactos ambientais e sociais dos monocultivos de eucalipto levou o Tribunal de Justiça do Estado de São Paulo (TJSP) a 
conceder, desde 2009, liminares restringindo atividades de plantio, corte, retirada e transporte desta cultura florestal nos municípios de Guaratinguetá, São Luiz do Paraitinga e Piquete.

Os argumentos que serviram de base para a decisão judicial do TJSP, de acordo com o processo $\mathrm{n}^{0}$ 0000950-48.2011.8.26.0220 do município de Guaratinguetá, os plantios de eucalipto têm provocado prejuízos ambientais e sociais, tais como redução no abastecimento de água potável, contaminação do lençol freático, êxodo de animais silvestres, descumprimento quanto à obrigação de restauração florestal em Áreas de Preservação Permanente, além do desemprego rural e contaminação de pessoas e animais por agrotóxicos (SÃO PAULO, 2011).

A partir deste caso, fica evidente que, mesmo frente às evidências das ciências ambientais e aos argumentos de importância econômica, os apelos da sociedade civil organizada seguem com forte influência sobre a arena ambiental. Sobre essa questão, trazemos à discussão o “princípio de precaução”. Segundo esse princípio, se há uma razão para suspeitar que uma substância em particular ou uma prática está ameaçando o ambiente, então uma ação deve ser tomada mesmo se a evidência não é clara.

Hannigan (2006) coloca os cientistas optando por uma posição reducionista frente ao problema, utilizando a instrumentação científico-metodológica para predizer riscos e suas probabilidades eventuais, deixando para os funcionários das agências e para os formuladores das políticas públicas a sensibilidade à pressão do público para agir antes cedo do que tarde. É o que se evidencia no caso do Vale do Paraíba.

\section{CONTRIBUIÇÃO TEÓRICA AO DEBATE}

Como proposta ao entendimento do diálogo aqui em construção, apresentamos um modelo analítico com objetivo de explicitar o papel da interdisciplinaridade em ambiente e sociedade na construção de novos olhares sobre um determinado tema, além de contribuir para a desconstrução de posicionamentos polarizados entre diferentes atores e grupos sociais envolvidos em conflitos de natureza socioambiental.

O modelo aqui apresentado foi pensado a partir da realidade estudada para este artigo, o que não exclui sua extrapolação para outros temas além da eucaliptocultura. Assim, o caso apresentado utiliza dois posicionamentos polarizados, um do setor agroindustrial florestal e outro dos movimentos sociais contrários à eucaliptocultura (Figura 1). 
No modelo, o uso das cores primárias azul e amarelo, locadas nos extremos da arena, representam cada um dos pólos participantes do conflito posto pelo tema. Quanto mais para os extremos, mais polarizados se tornam os discursos e menores são as possibilidades de um diálogo para a construção de consensos. O centro, na cor verde (a mistura homogênea entre o azul e o amarelo), é a representação do diálogo mediado pelo conhecimento interdisciplinar, capaz de ponderar os conhecimentos e diferentes pontos de vistas, norteadores do interesse de cada grupo.

O diálogo interdisciplinar, neste ponto, não difere da característica natural das cores. Ele é, em sua essência, a combinação de diferentes conhecimentos disciplinares, que, uma vez combinados, mudam sua configuração para a abertura a uma nova forma de conhecer a mesma realidade. Não obstante, é nesta região, onde encontra-se o conhecimento interdisciplinar, que surge espaço para diálogos menos polarizados ou mesmo despolarizados, onde a construção de consensos e a flexibilização dos atores envolvidos tornam-se possíveis.

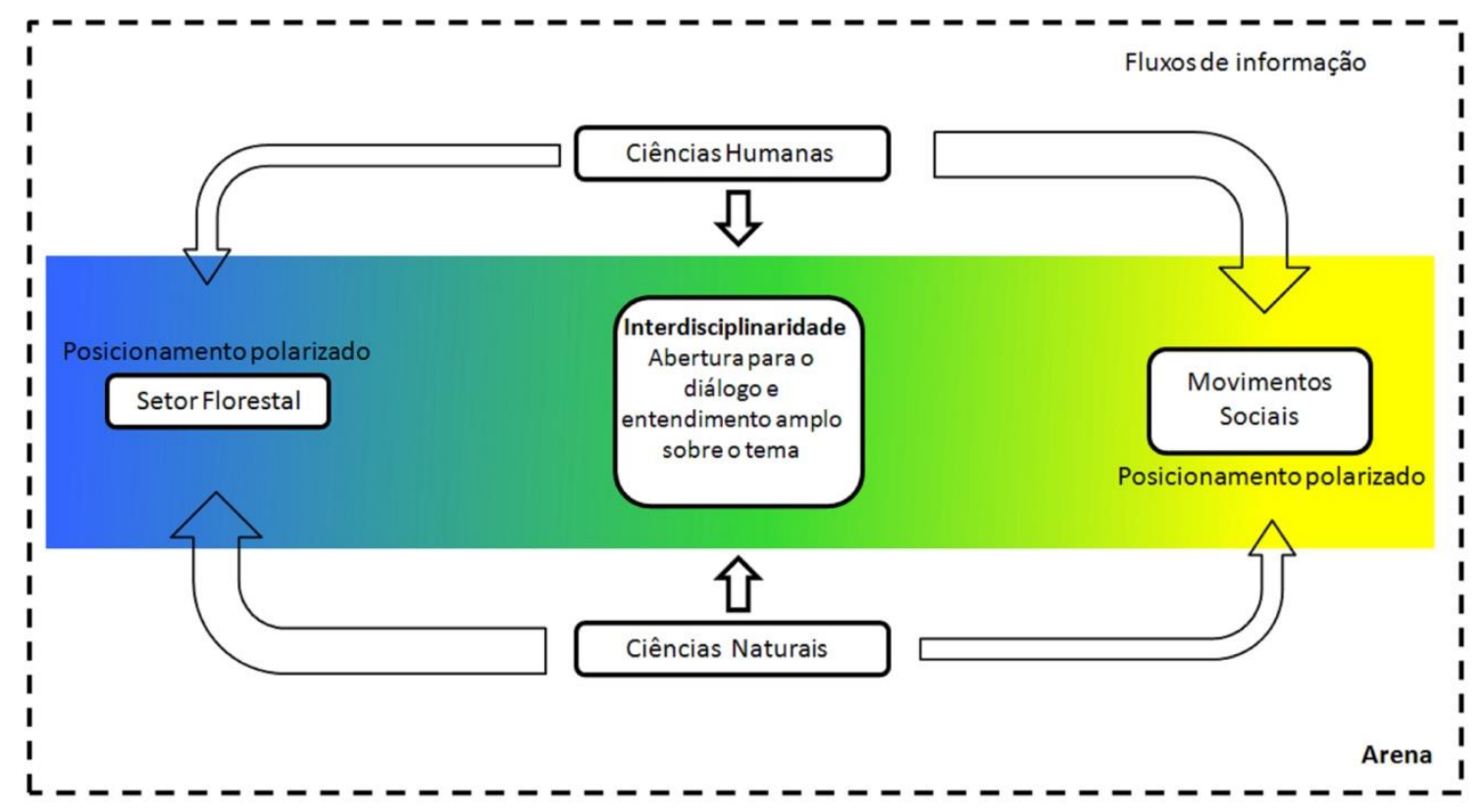

Figura 1. Modelo Analítico de Despolarização do Discurso (MADD).

As setas de fluxos de informação representam os inputs de conhecimento responsáveis por alimentar a formulação e construção dos argumentos de cada um dos setores envolvidos no debate sobre o tema e subsidiar a tomada de decisão. As setas de fluxo apontadas para o centro do diagrama representam o caminho do diálogo interdisciplinar, gerador de conhecimento e também alimentado pelas fontes de conhecimentos disciplinares. É neste campo, onde se encontra a interdisciplinaridade, que se estabelecem as oportunidades para a re-construção de discursos e posicionamentos, menos polarizados, ou até despolarizados. A proporção de tamanho entre as setas em direção aos posicionamentos polarizados a partir de cada uma das disciplinas do conhecimento, representa o fato de que há mais inputs das ciências naturais para subsidiar os argumentos do setor florestal enquanto que as ciências sociais oferecem mais inputs para subsidiar a construção de argumentos dos movimentos sociais. 


\section{CONSIDERAÇÕES FINAIS}

Na perspectiva de modernidade, assim como colocado por Giddens (1991), a política não pode ser pensada em base exclusivamente nacional ou local, mas deve ser tratada como uma sociedade civil onde defrontam-se projetos e visões distintas, antagônicas ou complementares.

Estabelecemos aqui uma proposta analítica para entender a indústria florestal do eucalipto numa perspectiva interdisciplinar em ambiente e sociedade utilizando os conceitos de reflexividade e arena e acreditando que esta abordagem permite apreender as diversas dimensões da questão ambiental. Ao reconhecer a dinâmica e flexibilidade dos atores e seus discursos, cujas posições mudam dependendo do conflito e as estratégias assumidas, o modelo proposto deve ser lido como uma ferramenta analítica a ser aperfeiçoada, na qual podem se integrar novos atores (como pode ser o Estado e as agências ambientais internacionais) e identificar novas posições possíveis dentro da arena.

Nesse sentido, iniciativas em governança ${ }^{9}$, endereçadas aos dilemas ambientais, resultado de pressões internacionais e também de setores da sociedade civil, têm oferecido alternativas mais sustentáveis e equitativas para o uso dos recursos naturais na América Latina. No entanto, recentes propostas de políticas públicas continuam a deixar claras as tensões entre os objetivos do desenvolvimento econômico, por um lado, e, por outro lado, os da inclusão social e da proteção ambiental (BAUD et al., 2011). Para refletir sobre essa questão, no caso brasileiro, vale a pena lembrar a atual discussão sobre a reforma do Código Florestal, a construção da usina hidrelétrica de Belo Monte ou mesmo o polêmico e histórico projeto de transposição do Rio São Francisco.

Em muitas regiões o impacto socioambiental dos monocultivos de eucalipto continua sendo amplamente debatido e, por esta razão, essa atividade agroindustrial florestal tem incentivado o desenvolvimento de diversas pesquisas científicas, o surgimento de mecanismos de mercado para que o setor atenda às demandas da sociedade e do comércio, e o embate entre diferentes atores envolvidos nesta área ambiental.

\footnotetext{
${ }^{9}$ A governança diz respeito aos processos decisórios e às ações voltadas à administração de problemas comuns (COMISSÃO SOBRE GOVERNANÇA GLOBAL, 1996).
} 
Nesse contexto, onde se enfrentam diferentes discursos e posicionamentos, construídos através do processo histórico de cada grupo social na sua relação com o modelo de desenvolvimento socioeconômico, se firmam as oportunidades para o diálogo e negociação, elementos chave para uma condução, com ampla participação da sociedade, do atual modelo de desenvolvimento para uma nova plataforma orientada nas bases da sustentabilidade.

Esta perspectiva de abertura e oportunidade ao diálogo se constitui parte fundamental do processo de formação de uma Governança Ambiental ${ }^{10}$ na América Latina, que se preocupará com a integração dos diversos sistemas de manejo, incluindo o amplo sistema ecológico e de atores sociais (BAUD et al., 2011). Estudos interdisciplinares em ambiente e sociedade podem dar significativa contribuição a esta arena, possibilitando a construção de discussões menos polarizadas e ancoradas nos conhecimentos gerados por diferentes disciplinas, de forma que a complexidade dos conflitos socioambientais seja melhor compreendida pelos atores envolvidos nos processos de negociação, refletindo no aumento da capacidade destes, para a tomada de decisões e para a formulação de agendas que conciliem desenvolvimento e qualidade de vida.

\section{Agradecimentos}

Agradecemos ao Núcleo de Estudos e Pesquisas Ambientais (NEPAM/UNICAMP) e às agências de fomento à pesquisa do Estado de São Paulo (FAPESP), à Coordenação de Pessoal de Nível Superior (CAPES) e à Comisión Nacional de Investigación Científica y Tecnológica de Chile (CONICYT).

\section{REFERÊNCIAS BIBLIOGRAFICAS}

ADEODATO, S. Pequeno produtor entra na busca pelo selo verde. Valor Econômico. São Paulo, setembro, 2011. Disponível em: <http://www.valor.com.br/brasil/1013666/pequenoprodutor-entra-na-busca-pelo-selo-verde> Acessado em: 22 de fevereiro de 2012.

\footnotetext{
${ }^{10}$ A Governança Ambiental leva em consideração o coletivo de capacidade a soluções-problemas dos diferentes atores sociais, na perspectiva de entender as interações sociais e os possíveis conflitos entre eles em um processo complexo e dinâmico (KOOIMAN et al., 2005).
} 
ALMEIDA, A. C.; SOARES, J. V. Comparação entre uso de água em plantações Eucalyptus grandis e a floresta ombrófila densa (Mata Atlântica) na costa leste do Brasil. Revista Árvore. Viçosa, v. 27, n. 2, p. 159-170. 2003.

ALVAREZ, S. E.; DAGNINO, E.; ESCOBAR, A. (org.) Cultura e política nos movimentos sociais latino-americanos: novas leituras. Belo Horizonte: UFMG, 2001. 538 p.

ANDREASSIAN, N. Water and forests: from historical controversy to scientific debate. Journal of Hydrology, 291: 1-27. 2004.

BAENA, E. S. A rentabilidade econômica da cultura do eucalipto e sua contribuição ao agronegócio brasileiro. Conhecimento Interativo. São José dos Pinhais, v. 1, n. 1, p. 3-9. 2005 .

BALBINOT, R.; OLIVEIRA, N. K.; VANZETTO, S. C.; PEDROSO, K.; VALERIO, A. F. O papel das florestas no ciclo hidrológico em bacias hidrográficas. Ambiência. Guarapuava, v. 4, n. 1, p. 131-149, jan./abr. 2008.

BAUD, M.; CASTRO, F.; HOGENBOON, B. Environmental Governance in Latin America: Towards an integrative Research Agenda. Eropean Review of Latin American and Caribbean Studies 90. Amsterdam: NALACS, p 79-88. 2011.

BECK, U. Risk Society: Towards a new modernity. Londres: Sage Publications. 1992. 232 p.

BECK, U. A reinvenção da política: rumo a uma teoria da modernização reflexiva. In: BECK, U.; GIDDENS, A.; LASH, S. Modernização reflexiva. São Paulo: Fundação Editora Unesp, 1995. p. 11-71.

BLANCO, D. N.; MENDES, J. N. Aproximaciones alanálisis de los conflictos ambientales em La Patagonia. Reflexiones de historia reciente 1980-2005. Ambiente e Sociedade. Campinas, v. 9, n. 2, p. 47-69. 2006.

CAMARGO, A. P.; CAMARGO, M. B. P. Uma revisão analítica da evapotranspiração potencial. Bragantia. Campinas, v. 59, n. 2, p. 125-137. 2000.

CANNELL, M. G. R. Environmental impacts of forest monocultures: water use, acidification, wildlife conservation, and carbon storage. New Forests. Amsterdam. n. 17, p. 239-262. 1999.

CAPRA, F. As conexões ocultas: ciência para uma vida sustentável. São Paulo: Cultrix, 2002. $296 \mathrm{p}$.

CARDOSO, P. A importância do eucalipto no Brasil. Painel Florestal, Campo Grande, cap. 1, março, 2011. Disponível em: <http://painelflorestal.com.br/noticias/australia/10971/aimportancia-do-eucalipto-no-brasil> Acesso em: 15 de fevereiro de 2012.

CHAVES, I. Povo Mapuche luta pelo direito à terra.A Nova Democracia, Rio de Janeiro, fevereiro, 2008. Disponível em: <http://www.anovademocracia.com.br/no-40/1520-povomapuche-luta-pelo-direito-a-terra>Acessado em: 18 de fevereiro de 2012.

COMISSÃO SOBRE GOVERNANÇA GLOBAL. Nossa Comunidade Global. Rio de Janeiro: Ed. FGV, 1996. 322 p.

COSTA, M. H.; FOLEY, J. A. Trends in the hydrologic cycle of the Amazon basin. Journal of Geophysical Research. v. 104, n. D12, p. 14,189-14,198, junho. 1999.

FERREIRA, L. C. Dimensões Humanas da Biodiversidade. Ambiente e Sociedade. Campinas,v. 7, n. 1, p. 47-66. 2004. 
FERREIRA, L. C. Idéias para uma Sociologia da Questão Ambiental no Brasil. São Paulo: Annablume, 2006. 110 p.

FOOD AND AGRICULTURE ORGANIZATION OF THE UNITED NATIONS - FAO. State of The World's Forests 2009. Roma. 2009.

FREITAS, G. J.; MARSON, A. A.; SOLERA, D. A. G. Os Eucalipto no Vale do Paraíba Paulista: Aspectos geográficos e históricos. Revista Geonorte. v. 1, n. 4, p. 221-237. 2012.

FUNDAÇÃO BRASILEIRA PARA O DESENVOLVIMENTO SUSTENTÁVEL - FBDS. Mudanças climáticas e eventos extremos no Brasil. São Paulo. 2011. 76 p.

GIDDENS, A. As conseqüiências da modernidade. São Paulo: Fundação Editora Unesp, 1991.

GUIMARÃES, R. P. Desarrollo sustentable en América Latina y el Caribe: desafíos y perspectivas a partir de Johannesburgo 2002. In: LIMONDA, H. Los tormentos de La materia. Aportes para una ecologia política latinoamericana. Héctor. Buenos Aires: CLACSO, 2002. p. 123-150.

HANNIGAN, J. Sociologia ambiental. Petrópolis, RJ: Vozes, 2006. 270 p.

IGLESIAS-TRABADO, G.; WILSTERMANN, D. Eucalyptus universalis. Global cultivated eucalypt forests map 2008. Version 1.0.1. In: GIT Forestry Consulting's

EUCALYPTOLOGICS: Information resources on Eucalyptus cultivation worldwide. 2008. Disponível em:

< http://git-forestry.com/download_git_eucalyptus_map_PT.htm> Acessado em: 22 de fevereiro de 2012.

KOOIMAN, J.; BAVINCK, M.; JENTOFT, S.; PULLIN, R.(eds.) Fish for Life: Interactive Governance for Fisheries. Amsterdam: Amsterdam University Press, 2005. 400 p.

LIMA, W. P. A silvicultura e a água: ciência, dogmas e desafio. In: PROCHNOW, M.

Cadernos do Diálogo, v. 1. Rio de Janeiro: Instituto Bioatlântica, p. 8-54.2010.

MARTINI, A. J. A Introdução do Eucalipto no Brasil completa 100 Anos. Blog Tudo Sobre Plantas, Rio Claro, outubro, 2010. Seção Artigos, Árvores, Cultivo, Meio Ambiente. Disponível em: <http://www.tudosobreplantas.com.br/blog/index.php/2010/10/25/aintroducao-do-eucalipto-no-brasil-completa-100-anos/> Acesso em: 15 de fevereiro de 2012.

MAZZOLLI, M. Mosaics of Exotic Forest Plantations and Native Forests as Habitat of Pumas. Environmental Management, v. 46, p. 237-253, 2010.

MORA, A.; GARCIA, C. H. A cultura do eucalipto no Brasil. São Paulo: Sociedade Brasileira de Silvicultura, 2000. 112 p.

MORAN, E. F.; OSTROM, E. Ecossistemas Florestais: interação homem-ambiente. São Paulo: Senac/Edusp, 2009, 544p.

OLIVEIRA, F. Luta contra o eucalipto se internacionaliza. FASE, Vitória, 2007. Disponível em: <http://www.fase.org.br/v2/pagina.php?id=1545>Acessado em: 10 de julho de 2011.

OLIVEIRA, L. M. T. Diagnóstico de fragmentos nativos, em nível de paisagem, em áreas sob influência da Vera Cruz Florestal, Eunápolis, BA. 1997. 74 f. Dissertação (Mestrado em Entomologia) - Universidade Federal de Viçosa, Viçosa, MG. 1997.

OSTROM, E. Governing the commons: the evolution of institutions for collective action. Cambridge University Press, 1990. 280 p. 
PINTO, L. P.; PENIDO, J. L. D. Apresentação. In: LIMA, W. P. A silvicultura e a água: ciência, dogmas e desafio. In: PROCHNOW, M. Cadernos do Diálogo, v. 1. Rio de Janeiro: Instituto Bioatlântica, 2010. p. 8-54.

REVISTA MADEIRA. Por que Usar Eucalipto? Revista Madeira, n. 75, agosto. 2003. Disponível em:<http://www.remade.com.br/br/revistadamadeira_materia.php?num=394\&subject=Caract er\%EDsticas\&title=Por\%20que\%20usar\%20eucalipto?> Acessado em: 22 de fevereiro de 2012.

RUTKOWSKI, E. W.; PEREIRA, A. S.; MELLO, L. F. Consumo sustentável: o gesto brusco para as mudanças globais? In: RUTKOWSKI, E. W. Mudanças climáticas e mudanças socioambientais globais: reflexões sobre alternativas de futuro. Brasília: UNESCO, IBECC, 2008. 113-122.

SÃo PAULO. Ação Civil Pública. Processo n ${ }^{0}$ 0000950-48.2011.8.26.0220 do município de Guaratinguetá. Assunto: Meio Ambiente. Disponível em:

$<$ https://esaj.tjsp.jus.br/cpo/pg/search.do?paginaConsulta=1\&localPesquisa.cdLocal=220\&cb Pesquisa=NMPARTE\&tipoNuProcesso $=$ SAJ \&dePesquisa $=$ Fibria $>$. Acessado em: 28 de maio de 2011.

SILVA, C. L.; MENDES, J. T. G. (Orgs.) Reflexões sobre o desenvolvimento sustentável: Agentes e Interações Sob A Ótica Multidisciplinar. Petrópolis, RJ: Vozes, 2005.

SILVEIRA, P. B. Mamíferos de médio e grande porte em florestas de eucalyptus ssp com diferentes densidades de sub-bosque no município de Itatinga, SP. 2005. 76 f. Dissertação (Mestrado em Recursos Florestais/Conservação de Ecossistemas Florestais) - Escola Superior de Agricultura "Luiz de Queiroz", Universidade de São Paulo, Piracicaba, 2005.

SOARES, N. S.; MOURA, A. D.; SILVA, M. L.; REZENDE, A. M. Fatores que contribuem para impulsionar o comércio internacional de produtos florestais brasileiros. Centro de Inteligência em Florestas, Viçosa, janeiro, 2011. Texto Técnico. Disponível em: <http://www.ciflorestas.com.br/arquivos/doc_fatores_brasileiros_9240.pdf> Acessado em: 22 de fevereiro de 2012.

TIMO, T. P. C. Mamíferos de Grande e Médio porte em áreas de cultivo de eucalipto das bacias do Alto Paranapanema e Médio Tietê, Estado de São Paulo. 2009. 111f. Tese (Doutorado em Ecologia Aplicada) - Escola Superior de Agricultura "Luiz de Queiroz", Universidade de São Paulo, Piracicaba, 2009.

TREVISAN, R. Estudo do balanço hídrico e da dinâmica do nitrogênio em uma microbacia com plantação florestal de eucalipto no litoral norte do Estado de São Paulo. 2010. 111f. Dissertação (Mestrado em Ciências/Química na Agricultura e Meio Ambiente) Escola Superior de Agricultura Luiz de Queiroz, Universidade de São Paulo, Piracicaba, 2010.

VELOSO, P. Chile: Monoculture tree plantations on Mapuche territory, certified by the FSC (Forest Stewardship Council)? Climate Connections, fevereiro, 2011. Disponível em: <http://climate-connections.org/2011/02/28/chile-monoculture-tree-plantations-on-mapucheterritory-certified-by-the-fsc-forest-stewardship-council/> Acessado em: 18 de fevereiro de 2012.

VITAL, M. H. F. Impacto Ambiental das Florestas de Eucalipto. Revista do BNDES, Rio de Janeiro. v. 14, n. 28, p. 235-276, dezembro. 2007. 
WHITEHEAD, D.; BEADLE, C.L. Physiological regulation of productivity and water use in Eucalyptus: a review. Forest Ecology and Management, 193: p. 113-140.2004. 